\title{
A GESTÃO DE PROJETOS SOCIAIS E A INSERÇÃO DE TÉCNICAS DO CONHECIMENTO APLICADAS A UM SISTEMA DE INFORMAÇÃO GERENCIAL
}

\section{SOCIAL PROJECT MANAGEMENT AND KNOWLEDGE TECHNIQUES APPLIED TO A MANAGEMENT INFORMATION SYSTEM}

\author{
Helen Fischer Günther ${ }^{1}$; Luis Moretto Neto ${ }^{2}$; Murialdo Loch ${ }^{3}$; Nikolai Dimitrii Albuquerque ${ }^{4}$ \\ ${ }^{1}$ Universidade Federal de Santa Catarina - UFSC - Florianópolis - Brasil \\ fghelen@yahoo.com.br \\ ${ }^{2}$ Universidade Federal de Santa Catarina - UFSC - Florianópolis - Brasil \\ moretto@cse.ufsc.br \\ ${ }^{3}$ Universidade Federal de Santa Catarina - UFSC - Florianópolis - Brasil \\ murialdosc@yahoo.com.br \\ ${ }^{4}$ Universidade Estácio de Sá - Florianópolis - Brasil \\ nikolai.albuquerque@innovit.com.br
}

\begin{abstract}
Resumo
As organizações que desenvolvem projetos sociais vêm demonstrando crescente interesse pela profissionalização e aprimoramento da gestão, freqüentemente por meio de instrumentos $e$ metodologias adequadas e construidas para a sua realidade. Nesse contexto, o presente artigo analisa a inserção de técnicas de gestão de projetos sociais aplicada a um Sistema de Informação Gerencial (SIG), apresentando funcionalidades já existentes e utilizadas e analisando-as, bem como propondo aprimoramentos, à luz das teorias estudadas (ARMANI, 2006; BRAUM; RIBEIRO, 2008; DAFT, 1999; NONAKA; TAKEUCHI, 1997). A pesquisa é caracterizada como documental, bibliográfica, descritiva, qualitativa e estudo de caso, cuja coleta de dados ocorreu por meio da observação direta aberta e a análise pautou-se nas seguintes categorias: forma, concepção, planejamento, realização, acompanhamento e conclusão. Diante disso, pode-se inferir que o sistema Gestor Social apresenta os seguintes índices de aderência às fases da gestão de projetos sociais: Concepção - 33,33\%; Planejamento - 28,57; Realização - 57,14\%; Acompanhamento $40 \%$; e Conclusão - 50\%, caracterizando-o como parcialmente aderente às necessidades de gestão de projetos sociais, sob um indice geral de $34 \%$.
\end{abstract}

Palavras-chave: organizações do terceiro setor; gestão de projetos sociais; sistemas de informação gerencial.

\section{Introdução}

As mudanças, as alterações sociais e econômicas, inerentes ao mundo contemporâneo, influenciam o ambiente organizacional. Em 1950, a ordem era produzir com maior resultado operacional, tendo como fator competitivo o aumento da eficiência. Durante as décadas de 60 e 70 , 
os programas de aquisição e diversificação foram decisivos para o lucro e o crescimento. Na década de 80, mudar era permanecer no negócio, ou seja, o lema das organizações era concentrar-se naquilo que se conhecia e terceirizar o que não pertencia ao núcleo de atividades da organização. Já na década de 90, a atenção voltou-se para os processos produtivos e para a melhoria da qualidade fatores que ocuparam lugar de destaque, pois somente assim seria possível competir com produtos melhores e mais baratos.

Desta forma, no início da década de 90, com o avanço da tecnologia digital, houve o surgimento de novos produtos, profissões e mercados. A economia passa a fundamentar-se em dois pilares: tecnologias digitais e conhecimento. Para Drucker (2000, p. 10), as empresas têm poucas escolhas, "senão a de se converter em organizações baseadas em informações". O autor completa que "o centro de gravidade do emprego desloca-se rapidamente de trabalhadores manuais e pessoal de escritório para trabalhadores do conhecimento". Senge (2000) confirma a mesma tese quando comenta que a essência para uma organização permanecer competitiva é o investimento em conhecimento e aprendizagem.

Tal cenário também impacta a percepção das organizações do terceiro setor (OTS) que, em geral, vêm demonstrando interesse crescente no aprimoramento da gestão, ora elaborando suas próprias práticas, ora adaptando as já consagradas práticas da administração empresarial. Desta maneira, as OTS buscam cada vez mais atingir seu propósito utilizando-se de ferramentas de gestão computacionais, agregando funcionalidades como gestão dos projetos, prestação de contas, gestão operacional e financeira, gerenciamento do investimento social, controle e avaliação de indicadores.

Neste contexto se faz necessário desenvolver ferramentas de geração, disseminação, aplicação e comprovação do conhecimento, que reflitam a maneira de ser de cada organização. Dessa forma, o presente estudo objetiva analisar a inserção de técnicas de Gestão do Conhecimento (GC) aplicadas a um Sistema de Informação Gerencial (SIG) focado em projetos sociais, de modo a apresentar funcionalidades já existentes e utilizadas e analisá-las, bem como propor aprimoramentos, à luz das teorias estudadas.

\section{Gestão de projetos sociais e gestão do conhecimento}

As organizações devem manter seus produtos em constante desenvolvimento, tanto quanto seus serviços em permanente aprimoramento. Essa postura advém da concorrência nos mercados contemporâneos. Para Gattoni (2006, p. 3) os fatores “demanda exponencial pela competitividade como o excesso de alternativas de parceiros, fornecedores e componentes essenciais oferecidos sob a forma de produtos e serviços de agregação de valor" despontam o surgimento de uma estruturação organizacional adaptada para essa nova forma de gestão. É necessário, de acordo com o autor, 
flexibilidade, agilidade e o caráter da temporalidade, uma vez que cada nova solução deve ser única, individual e, via de regra, original, o que requer gestão efetiva dos projetos relacionados.

Este cenário também se configura para as organizações do terceiro setor, cuja concorrência ocorre basicamente por recursos a serem captados, nacional e internacionalmente. A agregação de valor pode se dar nas metodologias desenvolvidas para o alcance dos objetivos de transformação do indivíduo e da comunidade. A maneira de gerenciar os projetos e auferir indicadores realistas e significativos é um dos principais desafios.

Desta forma, a utilização de projetos sociais é recorrente nos três setores da sociedade atual, com vistas à melhoria do entorno no qual se inserem e, especialmente, com vistas à sustentabilidade. A evidência dessa utilização no Brasil está na década passada, conforme narra Rodrigues (1998, p. 39):

As ONGs dos anos 90 aprenderam a linguagem dos 'projetos' e fazem deles seu principal instrumento de reprodução institucional, na medida em que guiam suas ações por objetivos claros e quantificáveis, aliados a cronogramas controláveis. Cada vez mais com mão-deobra profissional.

Rodrigues (1998) comenta que o governo brasileiro, a partir de sua reforma, apresenta maior descentralização e atenção ao controle de resultados, especialmente no campo da gestão social, cujo elemento central é o projeto social.

No entanto, não é somente o governo que trabalha com projetos sociais, as empresas também o fazem. Como decorrência, as organizações do terceiro setor elaboram e submetem seus projetos para captação de recursos, a exemplo dos Conselhos da Criança e do Adolescente (CDCA) - exemplo de pilar que sustenta o "Estado do Bem-Estar" (FADUL, 1999) -, Petrobras (objetivando maior efetividade em seus investimentos sociais), Instituto HSBC de Solidariedade (com editais específicos) e a Fundação Mauricio Sirotsky Sobrinho (por meio do Portal Social com captação de recursos online). Desta maneira, percebe-se que os projetos sociais permeiam a atuação do terceiro setor brasileiro, contribuindo para sua caracterização. Mas, o que é um projeto social?

Projeto social é conceituado pela Organização das Nações Unidas (ONU) como um conjunto de atividades inter-relacionadas e coordenadas, com vistas ao alcance de objetivos específicos, com tempo e orçamento delimitados (DUPRAT, 2005; KISIL, 2004). Tancredi e Kisil (1996, p.4 apud FRASSON, 2002, p. 62) colocam o projeto social como "um esforço para acelerar o desenvolvimento humano através da busca de soluções alternativas e inovadoras para problemas sociais identificados, reconhecidos e não-solucionados”.

Schermerhorn complementa tais conceitos ao mencionar que os projetos são importantes para aplicação em comitês, forças-tarefa, equipes e grupos multifuncionais em geral - os quais estão 
presentes nas organizações contemporâneas - pela flexibilidade que conferem à gestão. Além disso, os projetos são considerados "tanto um recurso de planejamento quanto uma base para prestação de contas" (SCHERMERHORN, 1999, p. 98).

Conceitos também utilizados no Brasil sobre projetos e seu gerenciamento podem ser extraídos da Cartilha Didática Gerenciamento de Projetos para o Terceiro Setor, elaborado pelo capítulo do Project Management Institute (PMI) no Rio de Janeiro, que apresenta metodologia própria para o referido tema.

Nesse sentido, um projeto é definido como "esforço temporário, planejado, executado e controlado, empreendido com o objetivo de criar um produto ou um serviço exclusivo" (BRAUM; RIBEIRO, 2008, p. 6). Ora, há indícios de que cada vez mais as organizações entendem a gestão de projetos como aliada no bom andamento dos objetivos. Entretanto, Gattoni (2006, p. 3) destaca que:

\footnotetext{
“a gerência de projetos não considera, pelo menos em caráter formal, a gestão do conhecimento desenvolvido pelas equipes de projeto, nem tampouco no relacionamento destas equipes de projeto com o restante da organização, ou com os eventuais parceiros, clientes e fornecedores envolvidos na condução de cada empreendimento a ser conduzido conjuntamente".
}

Insere-se, então, a Gestão do Conhecimento (GC) como um componente a ser considerado no âmbito da gestão de projetos, firmando-se no início da década de 1990, tornando-se parte das estratégias organizacionais.

Davenport e Prusak (1998) referem-se à GC como a reunião de todas as tarefas que envolvam a geração, codificação e transferência do conhecimento, Teixeira Filho (2000, p. 22) argumenta semelhantemente: "a gestão do conhecimento pode ser vista como uma coleção de processos que governa a criação, disseminação e utilização do conhecimento", visando atingir os objetivos organizacionais.

Probst (2002), aborda características mais específicas, de que o conhecimento baseia-se em dados e informações, sempre ligado às pessoas, construído por indivíduos e representando suas crenças sobre relacionamentos causais, cuja descrição Sveiby (1998) torna mais subjetiva, ao mencionar a GC como a arte de criar valor com os ativos intangíveis de uma organização. Por fim, Terra e Gordon (2002, p. 57), apontam que "a gestão do conhecimento, em seu sentido mais atual, pode ser considerada o esforço para melhorar o desempenho humano e organizacional por meio de facilitações de conexões significativas".

Para Quinn (1992), muito mais do que ativos imobilizados, como equipamentos, instalações e imóveis, são as capacidades intelectuais que contam para o poder econômico e de produção das empresas. Convergentemente, Toffler (1994) aponta que o conhecimento é o substituto definitivo de outros recursos, alçando-o à condição de fonte de poder da mais alta qualidade. Isso pode explicar o 
porquê das disputas pelo controle e intensificação do conhecimento organizacional nas últimas décadas. Para Davenport e Prusak (1999), a gestão do conhecimento compõe-se de, pelo menos, três etapas, não necessariamente consecutivas ou ordenadas: geração, codificação e transferência do conhecimento.

Para Gattoni (2006) a metodologia de gerenciamento do PMI privilegia fortemente a troca das informações referentes aos projetos, mas oferece uma ênfase muito menor ao tratamento do conhecimento embutido nas pessoas envolvidas direta ou indiretamente. De acordo com Nonaka e Takeuchi (1997) “o gerente médio passa a ter um papel fundamental no processo de gestão do conhecimento organizacional".

O processo gerencial proposto por Nonaka e Takeuchi (1997) é denominado middle-updown, que entende os funcionários de linha de frente como os maiores especialistas da organização quanto à realidade dos negócios em que ela se envolve. Por isso, segundo os autores, a "principal tarefa dos gerentes de nível médio na gerência middle-up-down é orientar essa situação caótica em direção à criação proveitosa do conhecimento".

A aplicação de técnicas de GC aos projetos, elucida Gattoni (2006, p. 15), contribui para que as histórias de sucesso e fracasso que ocorreram ao longo de um projeto, as determinações, os problemas e falhas, as decisões, os resultados de reuniões, os conflitos e as soluções desenvolvidas podem e devem ser re-utilizados como subsídios e insumos para projetos seguintes. Dessa forma, o gerente de projeto pode buscar na Gestão do Conhecimento uma fonte para contínua melhoria.

\section{0 processo de gestão de projetos sociais}

Percebe-se o crescente número de OTS que realizam suas ações e obtêm recursos por meio de projetos sociais, e o número de instituições financiadoras dos mesmos, onde "o próprio nível de exigência geral quanto à qualidade da ação social é, hoje, maior do que nunca" (ARMANI, 2006, p. 14). Isso ocorre em parte devido ao aumento da demanda por recursos dentro de sua disponibilidade e quantidade limitada, senão escassa. e, concordante a isso, Adulis (2001) coloca o crescimento dessa demanda na medida em que:

a) Os financiadores se tornam céticos no tocante ao valor destinado às organizações dos países em desenvolvimento, reduzindo, portanto, o volume de recursos destinados;

b) A busca cada vez mais concorrida por recursos, dificultando a captação dos mesmos e, concomitantemente, pressionando para a profissionalização; e

c) A transparência advinda do aumento da participação social, conferindo melhores condições de monitoramento da aplicação dos recursos de ordem pública. 
Desta forma, torna-se cada vez mais imperativo o gerenciamento profissional dos projetos sociais, pois aplica aos mesmos conhecimentos, habilidades, ferramentas e técnicas, de maneira a atender seus propósitos (BRAUM; RIBEIRO, 2008) - norteados por valores e objetivos da organização e dos participantes - assim como melhorar o processo envolvido.

Há, então, diferentes abordagens acerca da elaboração e a posterior gestão dos projetos sociais. A escassez de literatura específica disponível e acessível sobre gestão de projetos sociais direciona as bases de tal estudo para duas referências: Braum e Ribeiro (2008), com uma visão bastante prática e burocrática da gestão de projetos em OTS e Armani (2006) que traz a visão do Marco Lógico, metodologia bastante utilizada por financiadores estrangeiros - organizações da cooperação internacional bilateral (órgãos do governo) e multilateral (instituições globais, UNICEF, Banco Mundial, BID, União Européia) - sendo reconhecida no Brasil também.

O Marco Lógico foi desenvolvido na década de 1970, fundamentado no sistema de análise de projetos da Agência dos Estados Unidos para o Desenvolvimento Internacional (United States Agency for International Development - USAID) e é caracterizado por uma matriz cujo principal objetivo é "oferecer uma estrutura lógica comum e possibilitar uma síntese das informações sobre os projetos" (ADULIS, 2001, p. 1-2), ou seja, "uma ferramenta para facilitar o processo de concepção, desenho, execução e avaliação de projetos e programas".

Armani (2006, p. 36) aponta que o Marco Lógico, esquematizado na figura 1, é composto por uma matriz de 16 células e "oferece uma sucessão de passos lógicos encadeados, ao final da qual se tem um projeto bem estruturado nas suas relações de causa e efeito". A composição das 16 células podem ser identificadas no quadro a seguir, sendo que a orientação de construção da matriz é ilustrada por números e setas azuis e a leitura segue as direções apontadas pelas setas de cor laranja (ARMANI, 2006). 
Figura 1- Matriz do Marco Lógico

\begin{tabular}{|c|c|c|c|c|}
\hline & $\begin{array}{l}\text { 1) Descrição } \\
\text { Sumária }\end{array}$ & $\begin{array}{l}\text { 3) Indicadores } \\
\text { verificáveis }\end{array}$ & $\rightarrow \begin{array}{l}\text { 4) Meios de } \\
\text { Verificação }\end{array}$ & 2) Premissas \\
\hline Impactos & $\begin{array}{l}\text { Objetivo Geral: } \\
\text { objetivo amplo para } \\
\text { o qual o objetivo do } \\
\text { projeto contribui. }\end{array}$ & $\begin{array}{l}\text { De Impacto: } \\
\text { Evidenciam a } \\
\text { contribuição de.- } \\
\text { projeto para o } \\
\text { alcance do Objetivo } \\
\text { geral. }\end{array}$ & $\begin{array}{l}\text { Fontes de dados e } \\
\text { informaçə̃ese } \\
\text { meios de registro } \\
\text { para avaliação do } \\
\text { Impacto. }\end{array}$ & $\ldots \ldots$ \\
\hline Resultados & $\begin{array}{l}\text { Objetivo do Projeto: } \\
\text { Objetivo específico } \\
\text { do projeto. Sua } \\
\text { finalidade. }\end{array}$ & $\begin{array}{l}\text { De Efetividade: } \\
\text { Evidenciam o grau } \\
\text { de realização do :- } \\
\text { Objetivo específico } \\
\text { do projeto. }\end{array}$ & $\begin{array}{l}\text { Fontes de dados e } \\
\text { informaçães e } \\
\text { meios de } \\
\text { coleta/registro para } \\
\text { avaliação da } \\
\text { Efetividade. }\end{array}$ & $\begin{array}{l}\text { Premissas } \overrightarrow{\text { sobre }} \\
\text { fatores externos, } \\
\text { que podem } \\
\text { condicionar o } \\
\text { Objetivo Geral. }\end{array}$ \\
\hline Componentes & $\begin{array}{l}\text { Resultados } \\
\text { Imediatos: Situações, } \\
\text { serviços, produtos do } \\
\text { projeto, como } \\
\text { condição à realização } \\
\text { do Objetivo do } \\
\text { Prejeto." }\end{array}$ & $\begin{array}{l}\text { De Desempenho: } \\
\text { Evidenciam em que } \\
\text { medida os } \\
\text { Resultados foram - } \\
\text { produzidos. }\end{array}$ & $\begin{array}{l}\text { Fontes de dados e } \\
\text { informações e. - - } \\
\text { meios de } \\
\text { coleta/registro para } \\
\text { o Indicador de } \\
\text { Desempenho. }\end{array}$ & $\begin{array}{l}\text { Premissas sobre } \\
\text { fatores externos, } \\
\text { mas que podem } \\
\text { condicionar os } \\
\text { Objetivos do } \\
\text { projeto. }\end{array}$ \\
\hline Atividades & $\begin{array}{l}\text { Atividades: Conjunto } \\
\text { de ações-chave } \\
\text { necessárias para } \\
\text { alcançar os } \\
\text { resultados. }\end{array}$ & $\begin{array}{l}\text { Operacionais: } \\
\text { Evidenciam a } \\
\text { realização das } \\
\text { Atividades. }\end{array}$ & $\begin{array}{l}\text { As fontes de } \\
\text { informações e } \\
\text { meios de } \\
\text { verificação são o } \\
\text { Orçamento e o } \\
\text { Cronograma. }\end{array}$ & $\begin{array}{l}\text { Premissas sobre } \\
\text { fatores externos, } \\
\text { que podem } \\
\text { condicionar os } \\
\text { Resultados. }\end{array}$ \\
\hline
\end{tabular}

Fonte: ARMANI (2006); ADULIS (2001).

O Marco lógico, por conseguinte, permite que se compreenda e se monitore os impactos dos projetos realizados, o aperfeiçoamento do processo com vistas à sua otimização, facilita a gestão do projeto em si e gera informações para o público interessado (comunidade, fisscalizadores, órgãos públicos, etc.) (ADULIS, 2001).

Deste modo, a gestão dos projetos sociais pode ser estruturada didaticamente por etapas, as quais variam de acordo com o autor estudado, ou com a metodologia específica adotada, além de outros fatores. Este estudo baseia-se no diálogo entre duas fontes de referência no tema: Braum e Ribeiro (2008) a partir do PMBOK, com a idéia que a gestão de projetos sociais pode ser realizada através das etapas: iniciação, planejamento, execução, controle e encerramento; e Armani (2006), baseado no Marco Lógico, colocando a gestão de projetos sociais composta também por um ciclo de cinco etapas: "a identificação, a elaboração, a aprovação, a implementação (com Monitoramento e Avaliação), a avaliação e o replanejamento" (ARMANI, 2006, p.30). 
Comparando-se as duas metodologias, percebe-se um caráter mais técnico, burocrático, processual e pragmático exposto por Braum e Ribeiro (2008), em detrimento de um caráter de simplicidade estrutural e burocracia secundária, com maior espaço para a subjetividade, cujo cerne é a efetividade do projeto.

Ainda assim, didaticamente se pode estabelecer uma equivalência entre as etapas mencionadas, a fim de atribuir uma maneira clara de comparação e organização das subseções do presente trabalho. Tal comparação é demonstrada no quadro um, o qual embasa a estrutura subseqüente.

Quadro 1- Comparação básica entre as etapas das duas metodologias-base com a organização do presente estudo

\begin{tabular}{cccc}
\hline Fase & Braum e Ribeiro (2008) & Armani (2006) & Presente Estudo \\
\hline 1 & Iniciação & Identificação/Replanejamento & Concepção \\
2 & Planejamento & Elaboração & Planejamento \\
3 & Execução & Aprovação & Realização \\
4 & Controle & Implementação (MeA) & Monitoramento/Avaliação \\
5 & Encerramento & Avaliação & Conclusão \\
\hline
\end{tabular}

Fonte: Elaborado pelos autores

Ressalta-se que a numeração de fases ou etapas apresenta meramente o caráter estruturante, ou seja, para permitir melhor compreensão do processo. Tal linearidade é rara no cotidiano das organizações, haja vista que há dinamicidade e certo grau de imprevisibilidade, além da aprendizagem e geração de conhecimento a cada atividade realizada, o que leva, muitas vezes, à revisão e aprimoramento de atividades anteriores.

Com relação à comparação propriamente dita, as fases de indicação 3 e 4 podem apresentar divergências, no tocante à nomenclatura e seus componentes, onde a fase de Implementação (MeA) de Armani (2006) equivale às fases de Execução e Controle da metodologia de Braum e Ribeiro (2008), pressupondo, todavia, o já cumprimento da fase de Aprovação daquele quando se considera a fase correspondente destes. O detalhamento dessas fases, que compreende concepção, planejamento, execução, controle e conclusão.

\subsection{Concepção}

A origem de um projeto se dá proativamente a partir de uma idéia ou de um interesse em realizar algo (ARMANI, 2006), ou de uma identificação de oportunidade, nos mais variados contextos (BRAUM; RIBEIRO, 2008), ou ainda reativamente a partir de um problema (KISIL, 2004; BRAUM; RIBEIRO, 2008).

Assim, é recorrente no terceiro setor organizações que são criadas a partir de um projeto e, neste caso, “o projeto se confunde com a razão de existir da organização" (BRAUM; RIBEIRO, 2008, p. 9). Como exemplo deste, tem-se a Fundação Projeto Pescar, instituída em 1995, originada 
do Projeto Pescar idealizado em 1976, que hoje trabalha em rede, sob os conceitos de tecnologia e franquia social e está presente em onze estados brasileiros, oito unidades na Argentina e uma no Paraguai.

Faz-se mister um bom entendimento da necessidade, do objetivo e do contexto relacionado ao projeto, analisando as informações existentes e verificando lições aprendidas com projetos semelhantes anteriores, bem como uma avaliação prévia no que tange a "custos, questões jurídicas, verba pleiteada, condições para recebimento, chances de aceitação da proposta, competência técnica para realizar na qualidade exigida e os principais riscos envolvidos no projeto" (BRAUM; RIBEIRO, 2008, p. 9).

Armani (2006) corrobora ao indicar que se examine a sustentabilidade da idéia do projeto, no tocante à viabilidade sob aspectos políticos, técnicos e financeiros e ao incluir um diagnóstico da problemática.

No tocante ao diagnóstico da problemática, Armani (2006) aponta que se formulam os objetivos, estratégias, resultados e atividades preferencialmente de maneira participativa, promovendo o levantamento de dados e das informações acerca dos beneficiários; a identificação de dinâmicas sociais, políticas, econômicas e culturais que expliquem a problemática; identificação e avaliação de iniciativas assemelhadas; percepção dos próprios beneficiários em relação ao tema; envolvimento dos atores sociais; e levantamento de bibliografia pertinente (tanto teórica, quanto prática).

Pode-se, a partir disso, elaborar a proposta do projeto, utilizada para obtenção de patrocínio, apoio ou mesmo para tomada de decisão sobre o próprio projeto. Tal estruturação, conforme Kisil (2004), inicia com a definição do projeto, que envolve a identificação do público-alvo, os resultados esperados e os princípios de trabalho.

Braum e Ribeiro (2008), por sua vez, sugerem a utilização de um documento intitulado Termo de Abertura do Projeto (TAP), que reúne todas as informações iniciais em seções específicas e pode ser utilizado para formalização da aprovação e do início do projeto.

\subsection{Planejamento}

O marco lógico orienta que o primeiro passo é a formulação do objetivo geral, dos objetivos do projeto (específico), do mapeamento dos resultados imediatos e das atividades, hierarquizados na matriz, na primeira coluna (Descrição Sumária). Braum e Ribeiro (2008) afirmam que se deve começar pela identificação de todos os envolvidos no projeto, de participantes a interessados (que Armani (2006) aloca na fase anterior), formando a equipe de planejamento do projeto.

Em seguida, os autores sugerem a elaboração da Estrutura Analítica do Projeto (EAP), que é a representação - em forma gráfica ou em uma lista - do escopo do projeto, cujo detalhamento e 
número de níveis são sujeitos à complexidade do próprio projeto e da necessidade de gerenciamento.

A EAP é convergente à proposta de Kisil (2004) de elaborar um plano de trabalho do projeto, explicitando os serviços que serão prestados, pois são esses que "servem a um determinado fim, a um determinado público-alvo, a determinadas necessidades sociais” (KISIL, 2004, p. 30).

A autora destaca a importância da correlação direta dos serviços com os objetivos. É necessário, então, estabelecer o que a autora chama de "procedimentos", que são as ações com tempo e local, atividades que detalhem cada ação e as pessoas envolvidas, assemelhando-se aos planejamentos tático-operacionais do ambiente empresarial.

Além disso, descrevem-se os métodos de trabalho visando coerência, consistência e racionalidade nas escolhas dos mesmos. Deste modo, a partir da estrutura definida, cada membro da equipe deve conhecer suas responsabilidades e participações no projeto. Braum e Ribeiro (2008) propõem a elaboração de uma Matriz de Atribuição e Responsabilidades, instrumento que organiza todas essas informações.

Em seguida, parte-se para a preparação do cronograma, momento em que é imprescindível o seqüenciamento correto das atividades do projeto e a delimitação de datas de início e término (BRAUM; RIBEIRO, 2008). Kisil (2004) complementa com a elaboração de um descritivo sobre a abrangência social e geográfica das atividades e serviços, onde se detalha as bases operacionais do projeto, o número e a localização dos beneficiários, ou seja, um mapa da intervenção proposta.

A próxima etapa se refere ao planejamento da comunicação do projeto, que envolve o mapeamento das informações que devem ser geradas, quando e onde o devem e para quem devem ser divulgadas (BRAUM; RIBEIRO, 2008). Kisil (2004, p. 43) denomina esta etapa de "disseminação", cujo objetivo é "tornar o projeto palpável à sociedade, que pode transformá-lo num novo modelo de trabalho", por meio de relatórios distintos para cada destinatário.

Faz-se necessário também, identificar os recursos físicos necessários por meio de uma lista de recursos cuja aquisição se dará através do projeto (ou por causa dele) e planeja-se como adquirilos. A partir disso, pode-se elaborar o orçamento, utilizando-se a estrutura de atividades já desenhada, distribuindo os custos necessários (recursos humanos, financeiros e materiais).

Para fins de gerenciamento, Kisil (2004) ressalta a importância da memória de cálculo (como os cálculos das rubricas foram feitos), do fluxo de desembolso e do financiamento decrescente (demonstrar diminuição da necessidade de recursos com o decorrer do projeto, indicando maior sustentabilidade das ações e independência aos recursos externos).

Realiza-se o planejamento da avaliação do projeto, de forma permanente (ou de processo ou monitoramento) ou periódica (de resultados). Aquela consiste no acompanhamento dos trabalhos em períodos curtos, medindo as conseqüências imediatas dos serviços, bem como identifica 
possíveis ações corretivas; esta é realizada na conclusão das etapas do projeto, medindo as conseqüências previstas nos objetivos e aponta resultados não-previstos e parciais.

Além disso, deve-se planejar a avaliação final (ou de impacto) algum tempo após o término do projeto, com medições dos resultados de longo prazo relativas aos objetivos amplos do projeto. Neste momento, são desenhados os indicadores e medidas de resultados, que podem ser objetivos e quantitativos ou subjetivos e qualitativos e devem se referir ao marco zero do projeto (KISIL, 2004).

Por fim, reúnem-se as informações e os documentos gerados em cada etapa, transformandoos no Plano de Gerenciamento do Projeto, Plano Operacional do Projeto ou simplesmente Plano do Projeto, formando a base para as fases subseqüentes da gestão dos projetos sociais.

\subsection{Realização}

A realização corresponde à execução do projeto que, de acordo com Braum e Ribeiro (2008, p. 29), consiste em "coordenar pessoas e recursos para pôr em prática o Plano de Gerenciamento de Projeto". É a fase que, normalmente, consome o maior número de recursos durante o projeto.

Aqui a responsabilidade do gestor do projeto é a de autorizar o início e o término das atividades planejadas, utilizar de maneira sustentada os recursos previstos, zelar pela comunicação entre os membros do projeto, atualizar o cronograma e documentar o que for necessário.

Ressalta-se a importância do respeito às formas de agir da organização e de seus indivíduos, que não necessitam mudar por causa do projeto. Há norteamentos que advêm do planejamento do projeto, mas considerando que também foi feito com respeito às peculiaridades da organização, e de maneira participativa, certamente refletem a forma de se trabalhar na mesma e compatibilizam bem as pessoas e suas características com as atividades programadas.

A base para a fase de execução é o próprio Plano do Projeto, especialmente as atividades correlacionadas aos responsáveis, pois contribui para a coordenação da equipe e a realização das tarefas. É importante que todos os envolvidos tenham acesso ao Plano do Projeto para que saibam de maneira precisa o que devem fazer, formas de monitoramento, recursos disponíveis, datas envolvidas, e demais aspectos.

\subsection{Monitoramento/avaliação}

A fase de Monitoramento/Avaliação geralmente ocorre concomitantemente à de Realização, especialmente porque enquanto algumas atividades são finalizadas, outras se iniciam. Desta maneira, esta fase consiste no monitoramento do andamento das atividades, comparando o que foi previsto com o que foi realizado, elaboração de relatórios de desempenho do projeto e de prestação 
de contas, identificar e ativar ações corretivas, além de identificar lições aprendidas no referido projeto (BRAUM; RIBEIRO, 2008).

Estas constituem registros de aprendizados ocorridos durante o projeto, com vistas ao aprimoramento dos próximos projetos e "possibilita a geração de uma base com informações históricas [...] contribuindo bastante para a replicação de casos de sucesso" (BRAUM; RIBEIRO, 2008, p. 33).

Armani (2006, p. 69) afirma que "uma ótima elaboração de um projeto não é suficiente para o seu êxito. Além de um projeto bem elaborado, é necessário um ágil e eficiente sistema de gerenciamento para 'controlar' a sua implementação".

Este autor enfatiza o Monitoramento (M) e a Avaliação (A) constantes das Atividades, Resultados e Objetivos, por intermédio dos Indicadores formulados e expressos no Marco Lógico, ou mesmo no Plano do Projeto.

Desta forma, o monitoramento e a avaliação são definidos como "um conjunto de procedimentos de acompanhamento e análise realizados ao longo da sua implementação, com o propósito de checar se as Atividades e Resultados realizados correspondem ao que foi planejado (M) e se os Objetivos previstos estão sendo alcançados (A)" (ARMANI, 2006, p. 69).

Kisil (2004) coloca que a avaliação periódica (ou de resultados) é realizada na conclusão das fases ou etapas do projeto, medindo as conseqüências previstas nos objetivos, apontando resultados não-previstos e parciais e, na conclusão do projeto, realiza-se a avaliação final (ou de impacto), descrita na próxima seção.

\subsection{Conclusão}

Esta fase de finalização envolve a preparação de um relatório final de avaliação dos resultados do projeto. Por conseguinte, finalizam-se e arquivam-se os demais documentos em aberto, até mesmo contratos, assim como se comunica às partes envolvidas que o projeto foi concluído. É importante que esta fase seja realizada a cada término de etapa do projeto como um todo, e não somente quando de sua conclusão final (BRAUM; RIBEIRO, 2008). As principais atividades residem no acompanhamento e avaliação do desempenho, registro de informações pertinentes e lições aprendidas, e outras atividades correlatas.

Kisil (2004) orienta que esta fase deve se estender até algum tempo após o término do projeto, com as atividades já concluídas, a fim de medir os resultados de longo prazo junto aos beneficiários e à sociedade, pois constituem o cerne do projeto social.

A conclusão do projeto, portanto, envolve a avaliação final do mesmo, com análise do real impacto com relação aos objetivos traçados no planejamento. Neste momento é imprescindível 
acessar as informações do projeto, análises, intervenções e resultados, além de uma específica avaliação de impacto.

Percebe-se que tais fases assemelham-se muito às funções clássicas da administração planejar, organizar, coordenar, controlar e comandar -, constituindo uma nova denominação às mesmas, como uma espécie de "atualização", uma nova roupagem, adaptada à contemporaneidade das organizações, seus desafios e idiossincrasias.

\section{Metodologia}

Os aspectos relacionados ao método de pesquisa utilizado caracterizam esta pesquisa como documental, bibliográfica, descritiva, qualitativa e estudo de caso. Utilizou-se documentos relacionados às investigações já realizadas sobre o tema, bem como à descrição do sistema de informações analisado. Fez-se um estudo das funcionalidades existentes no sistema, comparando-as àquelas identificadas a partir da teoria e do processo delineado.

A análise dos dados, no tocante ao desenho tecnológico da ferramenta, pautou-se essencialmente na dimensão Forma de O'Brien (2004 apud ANTUNES et al., 2008). No tocante à adequação da ferramenta ao processo apresentado, foram extraídas do mesmo as seguintes categorias de análise:

a) Concepção: Delineamentos Iniciais; Avaliação da Sustentabilidade; Diagnóstico da Problemática; Proposta do Projeto ou Termo de Abertura do Projeto (relatório).

b) Planejamento: Objetivo Geral; Objetivos Específicos; Estrutura Analítica do Projeto; Matriz de Atribuições e Responsabilidades; Cronograma; Premissas e Fatores de Risco; Comunicação; Aquisição; Orçamento; Avaliação do Projeto; Plano do Projeto (relatório).

c) Realização: Registros Operacionais.

d) Acompanhamento: Mensuração de Indicadores; Painel de Indicadores; Comparação Previsto x Realizado; Lições Aprendidas; Acompanhamento do Plano.

e) Conclusão: Avaliação de Impacto.

Gil (2007) corrobora tal estrutura, pois afirma que a análise de dados no estudo de caso envolve a categorização dos dados, a fim de que o pesquisador possa realizar conclusões a partir dos mesmos.

A limitação mais significativa com a qual se deparou este estudo foi a escassez de literatura específica sobre gestão de projetos sociais, a qual direcionou as bases de tal estudo para duas referências: Braum e Ribeiro (2008), com uma visão bastante prática e burocrática da gestão de projetos em OTS e Armani (2006) que traz a visão do Marco Lógico. 


\section{Resultados da análise do sistema}

O sistema de informação analisado (Gestor Social) se posiciona como software para gestão de projetos sociais e entidades sem fins econômicos e, objetiva, principalmente, conferir transparência, eficiência e credibilidade à mesma.

Constitui um sistema de informações gerenciais (SIG), pois opera a organização, o processamento e a integração de dados em todos os níveis administrativos, com vistas ao aprimoramento da função gerencial das atividades sociais da organização, transformando-os rápida e consistentemente em informações para a tomada de decisão e a comunicação organizacional (LACOMBE, 2004).

Tal sistema é composto por módulos, construídos e relacionados conforme a necessidade e as características gerenciais da instituição. Há um módulo cadastral, essencial em qualquer sistema, que centraliza as informações dos participantes dos projetos, com destaque para os beneficiários e colaboradores envolvidos.

Desta maneira, tem-se o acesso a dados estatísticos na mesma medida em que se mantém a individualidade dos atendimentos aos beneficiários, através de prontuários eletrônicos (ferramenta específica que auxilia a informatização dos registros de profissionais como médicos, fonoaudiólogos, assistentes sociais, etc., muito presentes nos projetos sociais). Tais funcionalidades contribuem para o gerenciamento de informações básicas dos projetos, especialmente no tocante ao beneficiário, ponto nevrálgico dos projetos sociais.

O módulo estrutural permite a organização e hierarquização dos programas e projetos da organização, de maneira a possibilitar tanto a análise isolada de determinado projeto, bem como a consolidada de um programa. Percebe-se adequação à etapa de concepção e planejamento dos projetos, através da qual são formulados os aspectos-chave e se desenham os procedimentos e seus detalhes, além de permitir a construção da Matriz de Atribuição e Responsabilidade.

As finanças contemplam módulo específico, que trata de questões fundamentais como contas a pagar e a receber e fluxo de caixa, possibilitando o monitoramento por centros de custo vinculados aos projetos estruturados. Neste caso, a elaboração de orçamento poderia ser incluída, juntamente com a memória de cálculo, fluxo de desembolso e evidenciação do financiamento decrescente.

Há uma seção do sistema cuja função se refere à utilização de questionários, com criação das perguntas (objetivas múltipla/única escolha, dissertativas, etc.), que podem ser organizadas em seções. Tal função é útil para o registro de avaliações sociais, aplicação e tabulação de resultados de pesquisas de campo, por exemplo, permitindo a obtenção de gráficos e índices estatísticos, contribuindo substancialmente para as etapas de Monitoramento/Avaliação e Conclusão. 
Por fim, tem-se o módulo de indicadores, utilizado para a obtenção direta de indicadores diversos, utilizados para a elaboração de relatórios, ou para a demonstração a investidores, por exemplo.

Assim, pode-se modelar os indicadores, alimentá-los e obtê-los automaticamente (conforme os dados registrados), visualizá-los graficamente (aspecto relevante para a gestão, apontado por Braum e Ribeiro (2008) e Tenório (2002), obter histórico e realizar um sem número de análises (como os fatores que afetam os custos dos projetos e da instituição).

Conforme metodologia deste estudo, a base para análise é o que a teoria sugere como ideal na gestão de projetos sociais, a partir da qual as demais categorias se desenrolam, informando o que o Gestor Social atende com relação à teoria (Gestor Social contempla), o que ele está além da teoria (Gestor Social suplanta) e, por fim, o que ele está aquém da teoria (Gestor Social não contempla). Tais informações encontram-se estruturadas no Quadro 2.

Quadro 2 - Análise geral do Gestor Social

\begin{tabular}{|c|c|c|c|c|}
\hline $\begin{array}{c}\text { Fase do processo de } \\
\text { gestão de projetos } \\
\text { sociais } \\
\end{array}$ & Teoria sugere & $\begin{array}{l}\text { Gestor Social } \\
\text { contempla }\end{array}$ & $\begin{array}{l}\text { Gestor Social } \\
\text { suplanta }\end{array}$ & $\begin{array}{c}\text { Gestor Social } \\
\text { não contempla }\end{array}$ \\
\hline \multirow{6}{*}{ CONCEPÇÃO } & Oportunidade de projeto & & & $\checkmark$ \\
\hline & $\begin{array}{l}\text { Objetivos, contexto e lições } \\
\text { aprendidas }\end{array}$ & & & $\checkmark$ \\
\hline & Avaliação de viabilidade & $\checkmark$ & & \\
\hline & $\begin{array}{l}\text { Processo participativo de } \\
\text { obtenção de informações }\end{array}$ & $\checkmark$ & & \\
\hline & Proposta preliminar & & & $\checkmark$ \\
\hline & TAP & & & $\checkmark$ \\
\hline \multirow{15}{*}{ Planejamento } & $\begin{array}{l}\text { Utilização/formatação da Matriz } \\
\text { Lógica }\end{array}$ & & & $\checkmark$ \\
\hline & $\begin{array}{l}\text { Identificação da equipe de } \\
\text { planejamento do projeto }\end{array}$ & $\checkmark$ & & \\
\hline & Estrutura Analítica do Projeto & $\checkmark$ & & \\
\hline & $\begin{array}{l}\text { Agendamento semanal das } \\
\text { realizações }\end{array}$ & & $\checkmark$ & \\
\hline & Procedimentos & & & $\checkmark$ \\
\hline & Correlação serviços e objetivos & & & $\checkmark$ \\
\hline & Descrição métodos de trabalho & & & $\checkmark$ \\
\hline & $\begin{array}{l}\text { Matriz de Atribuição e } \\
\text { Responsabilidades }\end{array}$ & & & $\checkmark$ \\
\hline & Seqüenciamento das atividades & & & $\checkmark$ \\
\hline & Elaboração do Cronograma & & & $\checkmark$ \\
\hline & Premissas e fatores de risco & & & $\checkmark$ \\
\hline & $\begin{array}{l}\text { Mapeamento das informações e } \\
\text { da comunicação }\end{array}$ & & & $\checkmark$ \\
\hline & Identificação de recursos físicos & & & $\checkmark$ \\
\hline & Orçamento & $\checkmark$ & & \\
\hline & Memória de cálculo & & & $\checkmark$ \\
\hline
\end{tabular}

Fonte: Elaborado pelos autores

Continua... 


\begin{tabular}{|c|c|c|c|c|}
\hline \multirow{3}{*}{ Planejamento } & Fluxo de desembolso & $\checkmark$ & & \\
\hline & Planejamento da avaliação & & & $\checkmark$ \\
\hline & Plano do Projeto & & & $\checkmark$ \\
\hline \multirow{6}{*}{ REALIZAÇÃO } & Coordenação de pessoas & & & $\checkmark$ \\
\hline & Coordenação de recursos & $\checkmark$ & & \\
\hline & Inscrições & & $\checkmark$ & \\
\hline & Acompanhamento Atividades & $\checkmark$ & & \\
\hline & Registros do Cronograma & & & $\checkmark$ \\
\hline & Registros financeiros & $\checkmark$ & & \\
\hline \multirow{10}{*}{ ACOMPANHAMENTO } & Relatórios de acompanhamento & $\checkmark$ & & \\
\hline & Pesquisas & $\checkmark$ & & \\
\hline & Gráficos & $\checkmark$ & & \\
\hline & Coleta e gestão de indicadores & & $\checkmark$ & \\
\hline & Periodicidade & $\checkmark$ & & \\
\hline & Acompanhamento Cronograma & & & $\checkmark$ \\
\hline & Previsto X Realizado & & & $\checkmark$ \\
\hline & Andamento das atividades & & & $\checkmark$ \\
\hline & Ações corretivas & & & $\checkmark$ \\
\hline & Lições aprendidas & & & $\checkmark$ \\
\hline \multirow{4}{*}{ CONCLUSÃO } & Relatório final de avaliação & & & $\checkmark$ \\
\hline & Comunicação & & & $\checkmark$ \\
\hline & Avaliação & $\checkmark$ & & \\
\hline & Resultados de longo prazo & $\checkmark$ & & \\
\hline
\end{tabular}

Fonte: Elaborado pelos autores

Com relação ao processo de gestão de projetos sociais, na fase de Concepção, o Gestor Social contempla apenas a Avaliação de Viabilidade Financeira e o Processo Participativo de Obtenção de Informações (33,33\% dos itens), não contemplando a Identificação de uma Oportunidade de Projeto, os Objetivos, Contexto e Lições Aprendidas, a Proposta Preliminar e o Termo de Abertura do Projeto.

A fase de Planejamento apresenta 28,57\% dos itens atendidos pelo Gestor Social, quais sejam: Identificação da Equipe de Planejamento do Projeto, Estrutura Analítica do Projeto, Pacote de Trabalho, Relatórios Customizados por Usuário, Orçamento e Fluxo de Desembolso. Apresenta uma funcionalidade não mencionada na teoria (Agendamento Semanal das Realizações).

Com relação a fase de Realização, o sistema em análise contempla funcionalidades para a Coordenação de Recursos, Acompanhamento das Atividades, Acessibilidade Total e Registros Financeiros, sob um índice de 57,14\%. Possui uma funcionalidade que suplanta a teoria, que é a de Registro de Inscrições de Beneficiários.

A fase de Acompanhamento é contemplada em $40 \%$ pelo Gestor Social, com funcionalidades de Relatórios de Acompanhamento, Pesquisas, Gráficos e Controle da Periodicidade. O sistema não contempla Acompanhamento do Cronograma, Previsto X realizado, Percentual de andamento das Atividades, Ações Corretivas e Lições Aprendidas. 
Por fim, a fase de Conclusão é atendida em 50\%, pois o sistema apresenta funcionalidades para Avaliação e Resultados de Longo Prazo, em detrimento de Relatório Final de Avaliação e Comunicação.

De maneira geral, o SIG em estudo apresenta um índice de aderência de 34\%, o que aponta para uma possibilidade considerável de melhorias a serem adotadas, visando à aderência total ao processo completo de gestão de projetos sociais, segundo as teorias analisadas.

A inclusão de um módulo que trabalhe a gestão do conhecimento deve abranger as seguintes áreas de conhecimento gerencial, conforme Gattoni (2004, p. 84):

a) Gerência de integração: inclui os processos para a coordenação dos diversos elementos de um projeto;

b) Gerência de escopo: considera os processos para assegurar que o projeto inclui todo o trabalho necessário e somente ele, de forma a permitir sua execução e conclusão com sucesso;

c) Gerência de tempo: incorpora os processos para a garantia de planejamento e execução do projeto dentro dos prazos previstos;

d) Gerência de custos: estabelece os processos para assegurar que o projeto seja desenvolvido dentro dos orçamentos estipulados originalmente;

e) Gerência da qualidade: inclui os processos para assegurar que os produtos e serviços do projeto atinjam os padrões de qualidade segundo os quais o projeto foi concebido;

f) Gerência de recursos humanos: considera os processos para assegurar o melhor emprego do pessoal envolvido no projeto;

g) Gerência de comunicações: incorpora os processos para assegurar o adequado planejamento, geração, armazenamento e disseminação de informações do projeto;

h) Gerência de riscos: estabelece os processos relacionados com a identificação, quantificação e análise de riscos do projeto, bem como o estabelecimento das contramedidas a serem tomadas quando da ocorrência de cada um dos fatores de risco levantados;

i) Gerência de suprimentos e contratação: envolve os processos necessários para a aquisição de bens e serviços de fora da organização, no que tange a parceiros e fornecedores de insumos para o projeto.

Ora, o Gestor Social já apresenta os itens 2 e 4, precisando incorporar os demais itens. Assim, o módulo de gestão do conhecimento apresentaria o perfil técnico e as competências de cada integrante da equipe, vinculando-se diagnóstico (situação atual), conseqüências, proposta da equipe do projeto e resultados obtidos (o que pode ser aprimorado para os projetos futuros). Sugere-se que 
sejam trabalhadas as seguintes técnicas de gestão do conhecimento: criação de mapas do conhecimento, repositórios do conhecimento e composição de equipes de projeto multidisciplinares.

Ressalta-se a comunicação entre os atores - aspecto clamado na atualidade - poderia ser melhor desenvolvida e estimulada por meio da ferramenta, disponibilizando as informações aos diversos públicos interessados nos projetos, por meio de controle de acesso (usuário e senha) ou da geração de relatórios virtuais personalizáveis conforme o perfil do interessado.

Nesse sentido, a aproximação entre financiadores, OTS e beneficiários pode ser estimulada através da ferramenta, proporcionando ambientes de interação entre as partes. Desta forma, a transparência seria alcançada de maneira muito mais efetiva, assim como os impactos previstos teriam muito mais capilaridade e reaplicabilidade.

\section{Considerações finais}

O terceiro setor amplia sua atuação mundialmente, captando recursos de diversas maneiras, como o projeto social, considerado como um conjunto de atividades inter-relacionadas e coordenadas, com vistas ao alcance de objetivos específicos, com tempo e orçamento delimitados (DUPRAT, 2005; KISIL, 2004), voltado ao desenvolvimento social. Pode, então, ser visto como forma eficaz e eficiente de realizar as ações sociais, atingir resultados esperados na missão institucional e contribuir para a sustentabilidade da mesma.

Com relação às teorias estudadas, percebe-se uma ênfase maior dos autores no tocante à elaboração dos projetos e à avaliação dos mesmos, naturalmente tratando a execução e o monitoramento de maneira mais superficial.

Isso pode ocorrer devido ao baixo grau de maturidade da gestão de projetos sociais no Brasil; ou devido às próprias características das organizações sociais de natureza substantiva, tratando o processo de maneira mais livre e aberta, direcionando esforços para planejar e avaliar os resultados do mesmo.

Contudo, é arriscado tratar a gestão de projetos desta maneira, uma vez que todas as fases têm igual importância no processo e, além disso, são interdependentes, o que aponta para que se uma fase é realizada de maneira menos estruturada, pode impactar nos resultados do projeto e em seu grau de sucesso. Assim, se a execução e o monitoramento são negligenciados, pode estar gerando um impacto negativo na avaliação conclusiva do projeto e no grau de mudança e impacto gerado.

A ferramenta em estudo é o Gestor Social, que se propõe a apoiar a gestão de projetos sociais e compõe-se pelos módulos Pessoa; Projetos Sociais; Financeiro; e, Questionários. Foi analisado com base nas necessidades supracitadas e nas características descritas, mostrando-se parcialmente aderente à gestão de projetos sociais pelas organizações do terceiro setor (OTS), com 
um índice de aderência de 34\%. Em contrapartida, demonstra potencial considerável de aprimoramento, com vistas à aderência total ao processo de gestão de projetos sociais.

Em contrapartida, ao analisar o sistema de informações, percebe-se que outras etapas não estão tão bem embasadas tecnologicamente, como a etapa de planejamento, a qual apresenta bastantes detalhes que, em sua maioria, ainda não estão refletidos na ferramenta analisada. Por conseguinte, há convergência no tocante a "lacunas" da teoria que podem ser sanadas pela tecnologia, especialmente na etapa de Monitoramento/Avaliação, bastante desenvolvida no sistema analisado.

Ressalta-se que o processo de gestão de projetos sociais ocorre de maneira fluida, sem marcações rígidas de início e fim, cujas atividades se entrelaçam e formam redes que envolvem os participantes, cada qual com sua experiência, seus conhecimentos e objetivos, que não devem ser desconsiderados em outros momentos.

Os resultados da análise indicam que há contribuições significativas na adoção de um SIG para o alcance pleno e efetivo do propósito dos projetos sociais, constituindo um instrumento que comporta metodologias adequadas e construídas para esta realidade específica.

$\mathrm{Na}$ mesma medida, a utilização de ferramentas informatizadas de gestão contribui para a profissionalização e amadurecimento gerencial dos envolvidos, uma vez que reflete boa parte dos processos comuns de planejamento operacional e provisão orçamentária, administração de pessoal, participação e comunicação, administração financeira e acompanhamento do desempenho.

A avaliação dos projetos sociais apresenta-se como uma das maiores contribuições percebidas, em seus três momentos: permanente (ou de processo ou monitoramento), periódica (de resultados) e final (ou de impacto), tanto de maneira objetivo-quantitativa quanto subjetivoqualitativa. Além disso, favorece-se o amadurecimento de outros aspectos gerenciais como o aprendizado e a gestão do conhecimento.

Por fim, considera-se que trabalhando técnicas de Gestão do Conhecimento nos projetos sociais garantirá que as melhores práticas de hoje formarão a base para o desenvolvimento de novos projetos - pautados pelos princípios da eficácia, eficiência e efetividade gerenciais - e também para a tomada de decisão futura. 


\begin{abstract}
The organizations that develop social projects are showing growing interest in professionalization and improvement of management, often by means of tools and methodologies and developed to its reality. In this context, this article examines the integration of technical's social project management applied to a Management Information System (MIS), showing existing features and analyzing them, as well as proposing improvements in the light of the theories (ARMANI, 2006; BRAUN, RIBEIRO, 2008; DAFT, 1999; NONAKA, TAKEUCHI, 1997). The research is characterized as a documentary, bibliographic, descriptive, qualitative and case study, whose data was collected through open direct observation and the analysis was based on the following categories: shape, design, planning, implementing, monitoring and conclusion. Thus, it can be inferred that the system Gestor Social has the following rates of adherence to the phases of social project management: Design - 33.33\%; Planning - 28.57; Organization - 57.14\%; Monitoring $40 \%$; and Conclusion - 50\%, characterizing it as partially adherent to the needs of social project management, under an overall mark of $34 \%$.
\end{abstract}

Key-words: third sector organizations; social project management; management information systems.

\title{
Referências
}

ADULIS, Dalberto. O Uso do Marco Lógico na Gestão e Avaliação de Projetos. In: Tema do mês de dezembro de 2001. RITS, 2001.

ARMANI, Domingo. Como elaborar projetos?: guia prático para elaboração e gestão de projetos sociais. Porto Alegre: Tomo Editorial, 2006.

BAYMA, Fátima. Capacitação de administradores para as organizações sem fins lucrativos. In: Revista de Administração Pública, Rio de Janeiro, v. 31, n. 6, nov./dez., 1997.

BRAUM, Luiz C.; RIBEIRO, Mozar. Cartilha Didática para Gerenciamento de Projetos para o Terceiro Setor. Rio de Janeiro: PMI-Rio. Disponível em <www.pmirio.org.br>. Acesso em: 27 mar. 2008.

CHIZZOTTI, Antonio. Pesquisa em Ciências Humanas e Sociais. 5ª Ed. São Paulo: Cortez, 2001.

DAFT, Richard L. Teoria e projeto das organizações. 6 6 $^{\text {a }}$ ed. Rio de Janeiro: LTC, 1999.

DRUCKER, Peter Ferdinand. Administração de Organizações sem fins lucrativos: princípios e práticas. $4^{\mathrm{a}}$ ed., São Paulo: Pioneira, 1997.

. Desafios gerenciais para o século XXI. São Paulo: Pioneira, 2000.

DUPRAT, Carla. A empresa na comunidade: um passo-a-passo para estimular sua participação social. São Paulo: Global, 2005.

FADUL, Elvia M. C. Reforma do estado e serviços públicos: transformação de um modelo ou adaptação a uma nova ordem social? In: Revista de Administração da Universidade de São Paulo, São Paulo, v. 34, n. 1, jan/mar, 1999.

FALCONER, Andreas P. A Promessa do Terceiro Setor: Um Estudo sobre a Construção do Papel das Organizações Sem Fins Lucrativos e do seu Campo de Gestão. Disponível em: < http://www.lasociedadcivil.org/uploads/ciberteca/andres_falconer.pdf>. Acesso em: 16 mar. 2008.

GATTONI, Roberto Luís Capuruço. Gerente de Projetos.

$<$ http://www.cidade.usp.br/projetos/dicionario/verb05/0013/index.htm> Acesso em: 07 dez. 2006 
GATTONI, Roberto Luís Capuruço. Gerente do Conhecimento - aplicado à prática da gerencia de projetos. - Belo Horizonte: FUMEC-FACE, C/ Arte. 2004.

GEUS, Arie De. A empresa viva: como as organizações podem aprender a prosperar e se perpetuar. Rio de Janeiro Campus, 1998.

LACOMBE, Francisco J. M. Dicionário de Administração. São Paulo: Saraiva, 2004.

NONAKA, I.; TAKEUCHI, H., Criação de Conhecimento na Empresa. Rio de Janeiro: Editora Campus, 1997.

PROBST, G.; RAUB, S.; ROMHARDT, K. Gestão do Conhecimento: os elementos construtivos do sucesso. Porto alegre: Bookman, 2002.

QUINN, Brian James; ANDERSON Philip; FINKELSTEIN, Sydney. In: SERRA, Afonso Celso da Cunha (Trad.). Gestão do conhecimento. Rio de Janeiro: Campus, 2000.

RODRIGUES, Maria Cecília P. Demandas sociais versus crise de financiamento: o papel do terceiro setor no Brasil. In: Revista de Administração Pública, Rio de Janeiro, v. 32, n. 5, set/out, 1998.

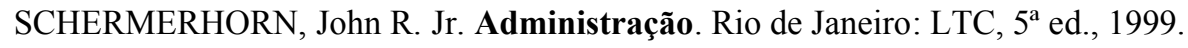

SENGE, Peter. A Quinta Disciplina: arte e prática da organização que aprende. 14. ed. São Paulo: Nova Cultural, 2000.

SVEIBY, Karl Erik. A nova riqueza das organizações. Gerenciando e avaliando patrimônios do conhecimento. Rio de Janeiro: Campus, 1998.

TEIXEIRA FILHO, J. Gerenciando conhecimento: como a empresa pode usar a memória organizacional e a inteligência competitiva no desenvolvimento de negócios. Rio de Janeiro: ed. SENAC, 2000.

TENÓRIO, Fernando G. Gestão de ONGs: principais funções gerenciais. Rio de Janeiro: FGV, 6ª ed., 2002.

TERRA, J. C. C. Gestão do conhecimento: o grande desafio empresarial: uma abordagem baseada no aprendizado e na criatividade. São Paulo: Negócio, 2001.

\section{Dados dos autores:}

Nome completo: Helen Fischer Günther

Filiação institucional: Universidade Federal de Santa Catarina

Departamento: Ciências da Administração

Função ou cargo ocupado: Mestranda

Endereço completo para correspondência: Universidade Federal de Santa Catarina, Centro SócioEconômico, Departamento de Ciências da Administração, sala 223. Bairro: Trindade - CEP: 88040900 - Florianópolis, SC, Brasil.

Telefones para contato: 5548 9945-7779

e-mail: fghelen@yahoo.com.br 
Nome completo: Luis Moretto Neto

Filiação institucional: Universidade Federal de Santa Catarina

Departamento: Ciências da Administração

Função ou cargo ocupado: Professor Associado II

Endereço completo para correspondência: Departamento de Ciências da Administração,Campus Universitário s/n, Bairro Trindade - CEP: 88040-900 - Florianópolis, SC, Brasil.

Telefones para contato: 5548 3721-6616

e-mail: moretto@.cse.ufsc.br

Nome completo: Murialdo Loch

Filiação institucional: Universidade Federal de Santa Catarina

Departamento: Engenharia e Gestão do Conhecimento

Função ou cargo ocupado: Mestrando

Endereço completo para correspondência: Universidade Federal de Santa Catarina, Centro Tecnológico CTC - Campus Universitário - Bairro: Trindade. CEP: 88040-970 - Florianópolis, SC, Brasil.

Telefones para contato: 5548 9916-2613

e-mail: murialdosc@yahoo.com.br

Nome completo: Nikolai Dimitrii Albuquerque

Filiação institucional: Faculdade Estácio de Sá

Departamento: Graduação em Sistemas de Informação

Função ou cargo ocupado: Professor Titular

Endereço completo para correspondência: Rua Prof. Ayrton Roberto de Oliveira, 32, $7^{\circ}$ andar Bairro: Itacorubi - Cep:88034-050 - Florianópolis-SC, Brasil

Telefones para contato: 55 (48) 3239-2500

e-mail: nikolai.albuquerque@innovit.com.br 
